\title{
PELATIHAN DAN PENDIDIKAN MEMPENGARUHI BIDAN PRAKTEK MANDIRI DALAM PEMBERIAN VITAMIN K 1 PADA BAYI BARU LAHIR DI KABUPATEN DELI SERDANG TAHUN 2013
}

\author{
Idau Ginting, Evi Desfauza, Elizawarda \\ Jurusan Farmasi Poltekkes Kemenkes Medan
}

\begin{abstract}
Abstrak
Angka kematian bayi (AKB) dan angka kematian balita (AKBAL) di Indonesia masih tergolong tinggi yaitu sekitar 34/1000 kelahiran hidup, terbesar masa neonatal yaitu sekitar 43\%. Menurut Riskesdas 2007, penyebab kematian neonatal yaitu asfiksia, prematuritas dan BBLR, sepsis, hipotermi, kelainan darah/Ikterus, postmatur dan kelainan kongenital. Salah satu bentuk dari kelainan darah pada neonatal adalah defisiensi vitamin K (PDVK). Kematian bayi dengan perdarahan intrakranial akibat PDVK sekitar $10-50 \%$ pada rentang umur 2 minggu sampai 6 bulan.Untuk mengetahui faktor yang mempengaruhi bidan praktik mandiri dalam pemberian Vit K1 di kabupaten Deliserdang tahun 2013, Hasil penelitian ini dapat memberikan informasi dan dapat digunakan untuk membuat suatu kebijakan. Rancangan penelitian ini menggunakan metode analitik dengan desain cross sectional, populasi adalah bidan praktek mandiri (BPM) di kabupaten Deli Serdang sebanyak 436 orang sampel sebanyak 82 orang, pengambilan sampel menggunakan metode simple random sampling dengan menggunakan tabel random C Survey, analisis data secara univariat, bivarial dan multivariat. Hasil penelitian dari analisis bivariat, ada 4 variabel yang berhubungan dengan pemberian vitamin $K_{1}$ pada bayi baru lahir adalah sikap dengan $p$ value 0,008 , lama bekerja $p$ value 0,016, pelatihan $\mathrm{p}$ value 0,000 , dukungan dari pihak terkait $\mathrm{p}$ value 0,38 dari uji regresi logistik $87,8 \% 4$ faktor yang memiliki pengaruh dalam pemberian vitamin $\mathrm{K}_{1}$ oleh bidan praktek mandiri pada bayi baru lahir yaitu pelatihan dengan nilai $B$ Expected paling besar 28,133, urutan kedua pendidikan nilai nilai B Expected 7,344, ketiga Lama bekerja nilai B Expected 6,130 dan urutan keempat Sikap nilai $B$ Expected 6,130. Pelatihan sangat dominan mempengaruhi pemberian vitamin K1pada bayi baru lahir, maka diharapkan pada organisasi profesi (IBI) agar lebih sering memberikan penyegaran pada BPM dengan mengikutsertakan BPM dalam pelatihan-pelatihan dan seminarseminar serta menguji pengetahuan dan sikap BPM yang berhungan dengan pertolongan persalinan dan bayi baru lahir pada saat memperpanjang surat izin praktek.
\end{abstract}

Kata Kunci : Pemberian suntikan Vitamin $\mathrm{K}_{1}$ Bidan Pratek Mandiri

\section{A. Latar Belakang}

Angka kematian bayi (AKB) di Indonesia masih tergolong tinggi yaitu sekitar 32/1000 kelahiran hidup (SDKI, 2012). Penyebab terbesar kematian balita terjadi pada masa neonatal yaitu sekitar 43 \%. Menurut Riskesdas (Riset Kesehatan Dasar) tahun 2010, ada beberapa penyebab kematian neonatal yaitu asfiksia, prematuritas dan BBLR, sepsis, hipotermi, kelainan darah/Ikterus, postmatur dan kelainan kongenital (Depkes, 2009).

Salah satu bentuk dari kelainan darah pada neonatal tersebut adalah penyakit defisiensi vitamin $\mathrm{K}$ (PDVK). Sebagai manifestasi dari PDVK tersebut bisa terjadi perdarahan intrakranial pada bayi baru lahir pada proses persalinan dan dan juga bisa perdarahan paska pemberian imunisasi hepatitis B 0 (HB 0) yang dikenal sebagai kejadian ikutan paska imunisasi (KIPI). Perdarahan intrakranial pada proses persalinan dapat menyebabkan kematian atau kecacatan fisik (Erik, 2003).

Angka kejadian PDVK pada bayi baru lahir berkisar antara 1:200 sampai 1:400 kelahiran bayi yang tidak mendapat suntikan vitamin K, dan Kematian bayi dengan perdarahan intrakranial akibat PDVK sekitar 10 - 50 \% pada rentang umur 2 minggu sampai 6 bulan, sedangkan kejadian ikutan paska imunisasi (KIPI) dengan perdarahan yang terjadi 2 jam sampai 8 hari akibat PDVK selama tahun 2003 sampai 2006 sebanyak 42 kasus dan 65 \% diantaranya meninggal (Depkes, 2009)

Upaya yang dilakukan oleh Depkes bersama tim teknis Health Technologi Assesment (HTA) Indonesia untuk mencegah kejadian PDVK ini adalah dengan merekomendasikan pemberian suntikan vitamin K1 pada semua bayi baru lahir. Pemberian suntikan vitamin $\mathrm{K}_{1} 1 \mathrm{mg}$ secara intra muskuler diberikan pada bayi setelah dilakukan inisisasi menyusui dini (IMD) 
selama 1 jam kerena sistem pencernaan pada bayi masih steril dan tidak adanya bakteri sintesis vitamin $\mathrm{K}$ yang bisa memproduksi vitamin $\mathrm{K}_{2}$. ASI oleh ibunya pun hanya mengandung sedikit vitamin K, Sehingga diperlukan tambahan vitamin $\mathrm{K}$ dari luar atau biasanya langsung sintesis yaitu vitamin $\mathrm{K}_{3}$. Atau pada banyak kasus, malah memberikan suntikan vitamin $\mathrm{K}_{1}$. Tentu diupayakan tubuh si bayi agar mampu mensintesa vitamin $\mathrm{K}_{1}$ tersebut tidak melalui usus. Bayi dapat mengalami pendarahan dalam karena berbagai macam sebab seperti adanya indikasi penyakit bawaan atau karena guncangan dari orang tuanya saat menggendong. Untuk itulah pemberian vitamin K pada bayi sangat diperlukan. Atau bayi mengalami penyakit sukarnya pembekuan darah (JNPK-KR, Depkes, 2008)

Bidan adalah salah satu profesi yang dapat bekerja (berpraktik) secara mandiri, salah satu kompetensi/kewenangan bidan dalam praktik mandiri tersebut adalah menolong persalinan normal termasuk memberikan suntikan Vitamin $\mathrm{K}_{1}$ dan imunisasi Hepatitis B 0 ( $\left.\begin{array}{lll}\mathrm{HB} & 0\end{array}\right)$ artinya dalam menolong persalinan normal tersebut bidan diharapkan dapat memberikan suntikan Vitamin $\mathrm{K}_{1} 1 \mathrm{mg}$ secara intra muskuler dan memberikan imunisasi HB 0 pada setiap bayi yang dilahirkan (Kemenkes, 2010)

Berdasarkan kunjungan penulis ke beberapa bidan praktik mandiri (BPM) menanyakan apakah telah melakukan penyutikan vit $\mathrm{K}_{1}$ pada bayi baru lahir, ternyata $60 \%$ bidan tersebut belum melakukan penyutikan Vitamin $\mathrm{K}_{1}$ pada setiap bayi baru lahir yang ditolongnya. Berdasarkan hal tersebut, timbul keinginan penulis untuk melakukan penelitian tentang faktor apa saja yang mempengaruhi bidan praktik mandiri dalam pemberian suntikan vitamin $\mathrm{K}_{1}$ pada bayi baru lahir di Kabupaten Deli Serdang tahun 2011.

\section{B. Metode Penelitan}

Penelitian ini dilakukan di kabupaten Deli Serdang dilakukan dari bulan Juni s/d November 2012, pengumpulan data dari bulan Juli s/d Oktober 2013

Rancangan penelitian ini bersifat analitik dengan desain cross sectional; sebagai variabel independen adalah pengetahuan, sikap, pendidikan, lama bekerja, pelatihan dan dukungan terhadap bidan praktik mandiri dan variabel dependen adalah pemberian suntikan vitamin $\mathrm{K}_{1}$.

Penelitian ini menggunakan data primer, alat pengumpulan data kuestioner menggunakan angket terbuka dan tertutup.

Populasi adalah seluruh Bidan Praktek Mandiri di Kabupaten Deli Serdang yang terdiri dari 436 orang Bidan Praktek Mandiri.

Besarnya sampel diambil berdasarkan teori Notoatmodjo (2005) dengan rumus:

$$
\mathrm{n}=\frac{\mathrm{N}}{1+\mathrm{N}\left(\mathrm{d}^{2}\right)}
$$

Analisis data dilakukan secara Analisis Univariat, Analisis Bivariat dengan menggunakan, dan multivariate menggunakan uji Regresi Logistik.

\section{Hasil penelitian dan Pembahasan}

\section{Analisis Univariat}

Gambaran dari faktor yang mempengaruhi Bidan Praktek Mandiri Memberikan Vitamin $\mathrm{K}_{1}$ akan dijabarkan pada tabel . 1

Tabel.1 Distribusi Responden Menurut Faktor yang Mempengaruhi Bidan Praktek Mandiri Memberikan Suntikan Vitamin $\mathbf{K}_{1}$ di Kabupaten Deli Serdang Tahun 2013

\begin{tabular}{|l|c|c|c|c|}
\hline \multirow{2}{*}{ Faktor } & \multicolumn{2}{|c|}{ Memberikan } & \multicolumn{3}{c|}{$\begin{array}{c}\text { Tidak } \\
\text { berikan }\end{array}$} \\
\cline { 2 - 5 } & N & \% & N & \% \\
\hline 1. Pengetahuan & & & & \\
\hline Baik & 34 & 75.6 & 11 & 24.4 \\
\hline Kurang & 21 & 56,8 & 16 & 43,2 \\
\hline 2. Sikap & & & & \\
\hline Mendukung & 49 & 74,2 & 17 & 25,8 \\
\hline Tidak Mendukung & 6 & 37,5 & 10 & 62,5 \\
\hline 3. Pendidikan & & & & \\
\hline D-III / D-IV & 50 & 70.4 & 21 & 29.6 \\
\hline D- I & 5 & 45.5 & 6 & 54.5 \\
\hline 4. Lama Bekerja & & & & \\
\hline D 5 th & 51 & 72,9 & 19 & 27,1 \\
\hline$\leq \quad$ 5 th & 4 & 33,3 & 8 & 66,7 \\
\hline 5. Pelatihan & & & & \\
\hline Ada & 50 & 87.7 & 7 & 12.3 \\
\hline Tidak ada & 5 & 20 & 20 & 80 \\
\hline 6. Dukungan & & & & \\
\hline Ada & 48 & 72,7 & 18 & 27,3 \\
\hline Tidak ada & 7 & 43,8 & 9 & 56,3 \\
\hline
\end{tabular}

Gambaran pengetahuan responden dapat dilihat pada tabel 4.1 kelompok yang memberikan suntikan vitamin $\mathrm{K}_{1}$ dan kelompok yang tidak memberikan suntikan vitamin $K_{1}$, responden yang berpengetahuan baik lebih banyak memberikan suntikan vitamin $\mathrm{K}_{1}$ daripada yang berpengetahuan kurang sebanyak 34 responden (75.6\%), responden yang berpengetahuan kurang lebih banyak tidak memberikan suntikan vitamin $\mathrm{K}_{1}$ pada bayi baru lahir.

Sebaran responden menurut sikap tentang pemberian suntikan vitamin $\mathrm{K}_{1}$ dapat dilihat pada tabel 4.1. sikap bidan praktek mandiri yang mendukung lebih banyak memberikan suntikan vitamin $\mathrm{K}_{1}$ pada bayi baru lahir sebanyak $49(74,2 \%)$ dan sikap bidan yang tidak mendukung lebih banyak tidak memberikan suntikan vitamin K1 sebanyak 10 responden (62,5\%).

Berdasarkan Pendidikan responden mayoritas berpendidikan D-III dan D-IV memberikan suntikan vitamin $\mathrm{K}_{1}$ pada bayi baru lahir dari pada berpendidikan Dl, yaitu sebanyak 50 responden (70.4\%), sedang yang berpendidikan D-I lebih banyak tidak memberikan suntikan vitamin $\mathrm{K}_{1}$ sebanyak 6 responden (54.5\%).

Berdasarkan lama bekerja responden ditemukan mayoritas lama bekerja bidan praktek mandiri $>5$ tahun memberikan suntikan vitamin $\mathrm{K}_{1}$ sebanyak 51 responden (72,9\%), sedangkan responden yang bekerja $\leq 5$ tahun mayoritas tidak memberikan suntikan vitamin $\mathrm{K}_{1}$ pada bayi baru lahir sebanyak 8 responden (66,7\%). 
Berdasarkan riwayat pelatihan mayoritas responden pernah mengikuti pelatihan yang relevan untuk pemberian suntikan vitamin $\mathrm{K}_{1}$ lebih banyak memberikan suntikan vitamin $\mathrm{K}_{1}$ pada bayi baru lahir sebanyak 50 responden (87.7\%), sedangkan responden yang tidak pernah mendapatkan pelatihan lebih banyak tidak memberikan suntikan vitamin $\mathrm{K}_{1}$ pada bayi baru lahir yaitu sebanyak 20 responden (80\%).

Berdasarkan dukungan yang diberikan mayoritas responden lebih banyak mendapatkan dukungan memberikan vitamin $\mathrm{K}_{1}$ pada bayi baru lahir sebanyak 48 responden (72,7\%), sedangkan responden yang tidak mendapat dukungan lebih banyak tidak memberikan sebanyak 9 responden (56,3\%).

\section{Analisis Bivariat}

Hubungan faktor yang mempengaruhi BPM Dengan Pemberian Vitamin $\mathrm{K}_{1}$ Pada Bayi Baru Lahir

Tabel 2. Hubungan, pengetahuan, Sikap, Pendidikan, Lama Bekerja, Pelatihan dan Dukungan BPM Dengan Pemberian Suntikan Vitamin $K_{1}$ Pada Bayi Baru Lahir di Kabupaten Deli Serdang Tahun 2013

\begin{tabular}{ccrcr}
\hline \multirow{2}{*}{$\begin{array}{c}\text { Variabel } \\
\text { Independen }\end{array}$} & $\begin{array}{c}\text { Memberikan } \\
\text { vit K }\end{array}$ & \multicolumn{2}{c}{$\begin{array}{c}\text { Tidak memberikan } \\
\text { Vit K }\end{array}$} \\
\cline { 2 - 5 } & $\mathrm{F}$ & $\%$ & $\mathrm{~F}$ & $\%$ \\
\hline
\end{tabular}

\begin{tabular}{lcccc}
\hline \multicolumn{5}{l}{ Pengetahuan responden } \\
Baik & 34 & 75,6 & 11 & 24,4 \\
Kurang & 21 & 56,8 & 16 & 43,2 \\
\hline \multicolumn{1}{c}{ Total } & 55 & 67,1 & 27 & 32,9 \\
\hline $\mathrm{X}^{2=}$ 3.249, & OR 2,35(0.919- 6.034) & P. 0,99
\end{tabular}

Sikap responden

$\begin{array}{lllll}\text { Mendukung } & 49 & 74,2 & 17 & 25,8\end{array}$

$\begin{array}{lllll}\text { Tidak } & 6 & 37,5 & 10 & 62,5\end{array}$

mendukung

\begin{tabular}{lcccc}
\multicolumn{1}{c}{ Total } & $\mathbf{5 5}$ & $\mathbf{6 7 , 1}$ & $\mathbf{2 7}$ & $\mathbf{3 2 , 9}$ \\
\hline $\mathrm{X}^{2} 7.872$ & OR. 4.804(1.517-15.213) & P.0.008 & \\
Pendidikan & responden & & & \\
D-III/D-IV & 50 & 70,4 & 21 & 29,6 \\
D-I & 5 & 45,5 & 6 & 54,5 \\
\hline Total & $\mathbf{5 5}$ & $\mathbf{6 7 , 1}$ & $\mathbf{2 7}$ & $\mathbf{3 2 , 9}$ \\
\hline $\mathrm{X}^{2} .2 .688$ & OR & $2.857(0.785-10.396$ & P. 0,165 &
\end{tabular}

Lama Bekerja

\begin{tabular}{ccccc}
$<5$ tahun & 51 & 72,9 & 19 & 27,1 \\
$\leq 5$ tahun & 4 & 33,3 & 8 & 66,7 \\
\hline Total & $\mathbf{5 5}$ & $\mathbf{6 7 , 1}$ & $\mathbf{2 7}$ & $\mathbf{3 2 , 9}$ \\
\hline $\mathrm{X}^{2}$ 7.246 & P. 0,009 & OR $=5.368(1.447-19.911)$ &
\end{tabular}

\section{Pelatihan}

\begin{tabular}{ccccc} 
Ada & 50 & 87,7 & 7 & 12,3 \\
Tidak Ada & 5 & 20 & 20 & 80 \\
\hline Total & 55 & $\mathbf{6 7 , 1}$ & $\mathbf{2 7}$ & $\mathbf{3 2 , 9}$ \\
\hline $\mathrm{X}^{2}$ 36.085 & P. 0,000 & OR= $28.571(8.110-100.661)$
\end{tabular}

\begin{tabular}{ccccc}
$\begin{array}{c}\text { Dukungan } \\
\text { Ada }\end{array}$ & $\mathbf{4 8}$ & $\mathbf{7 2 , 7}$ & $\mathbf{1 8}$ & $\mathbf{2 7 , 3}$ \\
Tidak Ada & $\mathbf{7}$ & $\mathbf{4 3 , 8}$ & $\mathbf{9}$ & $\mathbf{5 6 , 3}$ \\
\hline Total & $\mathbf{5 5}$ & $\mathbf{6 7 , 1}$ & $\mathbf{2 7}$ & $\mathbf{3 2 , 9}$ \\
\hline $\mathrm{X}^{2} 4.896$ & P. 0,038 & $\mathrm{OR}=3.429$ & $(1.111-0.577)$ &
\end{tabular}

\section{a. Pengaruh Pengetahuan BPM dengan pemberian Vitamin K1 pada bayi bayi baru lahir}

Berdasarkan analisis Bivariat dan multivariate tentang pengetahuan responden $P$ value 0,99 $(>0,05)$, berarti secara statistic tidak ada pengaruh yang signifikan antara pengetahuan BPM dengan pemberian suntikan vitamin $K_{1}$. Dengan demikian pengetahuan BPM tidak mempengaruhi dalam pemberian suntikan Vitamin $K_{1}$. Hal ini tidak sesuai dengan penelitian Budijanto (2008) yang mengatakan semakin tinggi tingkat pengetahuan bidan sangat mempengaruhi tingkat keterampilan dan juga penelitian ini teori Notoatmodjo (2003) yang menyatakan pengetahuan merupakan domain yang sangat penting dalam membentuk tindakan seseorang.

Dari hasil penelitian BPM yang memberikan suntikan vitamin $\mathrm{K}_{1}$ pada bayi sebanyak 55 orang yang berpengetahuan kurang sebanyak 21 orang (38,18\%), jika dibandingkan dengan sikap, BPM yang memberikan suntikan lebih banyak mendukung, dan pernah mendapatkan pelatihan APN hal ini mungkin disebabkan BPM yang kurang waktu untuk membaca dan melakukan pekerjaannya secara monoton sesuai dengan prosedur tetap yang sudah ditentukan.

\section{b. Pengaruh Sikap BPM terhadap Pemberian Vitamin $\mathrm{K}_{1}$ Pada Bayi Baru Lahir}

Berdasarkan analisis bivariat dan multivariat tentang sikap responden didapat $p$ value $<0,05$ berarti ada pengaruh sikap BPM terhadap pemberian suntikan vitamin $\mathrm{K}_{1}$, penelitian ini sesuai dengan teori Notoatmodjo (2003).

Sikap responden mayoritas mendukung terhadap pemberian suntikan vitamin $\mathrm{K}_{1}$ pada bayi baru lahir, hasil penelitian ini tidak sejalan dengan teori yaitu sikap mendukung yang dilandasi dengan pengetahuan yang baik, ternyata dari hasil penelitian ini pengetahuan responden masih ada yang kurang, namun sikapnya mendukung. Menurut B.F. Skinner (dalam, Azwar 2005) pembentukan sikap dipengaruhi pengalaman pribadi, karena sikap akan lebih mudah terbentuk apabila pengalaman pribadi tersebut dengan melibatkan faktor emosional. Sikap juga dapat timbul karena adanya pengaruh orang lain yang dianggap penting. Pada umumnya, individu bersikap konformis atau searah dengan sikap orang orang yang dianggapnya penting tersebut.. Kecenderungan ini antara lain dimotivasi oleh keinginan untuk berafiliasi dan keinginan untuk menghindari konflik dengan peraturan yang ada. Media massa sebagai sarana komunikasi, mempunyai pengaruh besar dalam pembentukan opini dan kepercayaan orang. Adanya informasi baru mengenai sesuatu hal memberikan landasan kognitif baru bagi terbentuknya sikap 
terhadap hal tersebut. Pesan-pesan sugestif yang dibawa informasi tersebut, apabila cukup kuat, akan memberi dasar afektif dalam mempersepsikan dan menilai sesuatu hal sehingga terbentuklah arah sikap tertentu. Selain itu juga jika bidan telah mendapatkan pelatihan dan dukungan yang mengharuskan setiap bayi baru lahir diberikan suntikan vitamin $\mathrm{K}_{1}$.

\section{c. Pengaruh Pendidikan Responden Terhadap Pemberian Suntikan Vitamin $K_{1}$ Pada Bayi Baru Lahir.}

Berdasarkan analisis bivariat tentang pendidikan responden didapat $p$ value 0,165 $>0,05$ berarti secara statistik tidak ada pengaruh pendidikan BPM terhadap pemberian suntikan vitamin $\mathrm{K}_{1}$ pada bayi baru lahir. Penelitian ini tidak sejalan dengan pendapat Arikunto (2002). Dari 82 responden 71 responden berpendidikan D-III dan D-IV dan sebanyak 21 orang (29,6\%) tidak memberikan suntikan Vitamin $\mathrm{K}_{1}$ pada bayi baru lahir, hal ini disebabkan masa kerjanya masih kurang 5 tahun dan pelatihan belum pernah didapat.

Namun Hasil analisis uji regresi logistic menunjukkan p. value 0.016 OR 9.328 berarti pemberian suntikan vitamin $\mathrm{K}_{1}$ pada bayi baru lahir 9.328 kali lebih pada BPM dengan pendidikan D-III/D-IV dibanding BPM pendidikan D-I, tingkat pendidikan juga merupakan salah satu faktor yang mempengaruhi persepsi seseorang untuk lebih mudah menerima ide-ide dan teknologi baru. Tingkat pendidikan seseorang dapat mendukung atau mempengaruhi tingkat pengetahuan seseorang, dan taraf pendidikan yang rendah selalu bergandengan dengan informasi dan pengetahuan yang terbatas. Makin tinggi tingkat pendidikan semakin tinggi pula pemahaman seseorang terhadap informasi yang didapat dan pengetahuan pun akan semakin tinggi. Berarti pendidikan memiliki peran penting dalam menentukan kualitas manusia.

\section{e. Pengaruh Lama Bekerja terhadap Pemberian Suntikan Vitamin $K_{1}$ Pada Bayi Baru Lahir}

Berdasarkan uji regresi Logistik bahwa lama bekerja BPM terhadap pemberian suntikan vitamin $\mathrm{K}_{1}$ pada bayi baru lahir nilai P $0.034(<0,5)$ dan OR 5,368 artinya secara statistic ada pengaruh lama bekerja BPM terhadap pemberian vitamin $\mathrm{K}_{1}$ pada bayi baru lahir. BPM yang masa kerjanya $>5$ tahun, memberikan vit K1 5,368 kali lebih dibandingkan BPM yang masa kerjanya $<5$ tahun.

Penelitian ini sesuai dengan penelitian yang dilakukan oleh Budijanto (2008) yang menyatakan masa kerja mempengaruhi bidan dalam melakukan tindakan dalam memantau dan melakukan tindakan persalinan yang diprogramkan dan pemberian suntikan vitamin $\mathrm{K}_{1}$ sudah merupakan kebiasaan dan merupakan peraturan dari Menteri Kesehatan.

Hal ini juga sejalan dengan pendapat Muchlas (2005) bahwa masa kerja merupakan indikator yang dapat mempengaruhi peningkatan kemampuan keterampilan seseorang. Semakin lama masa kerja seseorang tingkat kerampilan mengenai pekerjaanya akan meningkat.

\section{f. Pengaruh Pelatihan Terhadap Pemberian Vitamin $K_{1}$ pada Bayi Baru Lahir}

Berdasarkan uji regresi Logistik bahwa pelatihan terkait yang pernah diikuti BPM berpengaruh terhadap pemberian suntikan vitamin $\mathrm{K}_{1}$ pada bayi baru lahir dengan nilai P $0.000(<0,5)$ dan OR 28,571, artinya BPM yang pernah mengikuti pelatihan APN memberikan suntikan vitamin $\mathrm{K}_{1} \quad 28,571$ kali dibandingkan dengan BPM yang tidak pernah mendapat pelatihan APN.

Penelitian sesuai dengan penelitian yang dilakukan oleh Budijanto (2008) yang menyatakan bidan yang pernah mengikuti pelatihan APN tingkat kemahiran dan keterampilan dalam pemantauan dan bertindak semakin meningkat.

Pelatihan merupakan pengembangan ilmu dan tehnologi secara formal yang dilakukan oleh organisasi profesi atau oleh pemerintah karena adanya tuntutan pengembangan ilmu saat ini ataupun masa yang akan datang yang bersifat non karier ataupun peningkatan karier seseorang. Pelatihan merupakan pelatihan berbasis kompetensi yang bertujuan untuk meningkatkan kemampuan dan kemahiran bidan dalam melakukan tindakan kebidanan.

\section{f. Pengaruh Dukungan terhadap Pemberian Vitamin $K_{1}$ Pada Bayi baru Lahir}

Berdasarkan uji bivariat secara chi-square tentang dukungan dari pihak terkait yang diterima BPM terhadap pemberian suntikan vitamin $K_{1}$ pada bayi baru lahir dengan $p$ value $0,038(<0,5)$ artinya secara statistic ada hubungan dukungan yang diterima BPM dengan pemberian suntikan vitamin $\mathrm{K}_{1}$ pada bayi baru lahir.

Dari uji statistic regresi logistic diperoleh tidak adanya pengaruh antara dukungan pihak yang terkait dengan pemberian vitamin $\mathrm{K}_{1}$ oleh BPM dengan nilai P. 0.942,

Dukungan yang diberikan oleh atasan atau sejawat dapat meningkatkan rasa percaya diri dari BPM untuk memberikan suntikan vitamin $\mathrm{K}_{1}$. Menurut Sarafino dukungan adalah suatu bentuk kenyamanan, perhatian, penghargaan, ataupun bantuan yang diterima orang yang berarti, baik secara perorangan maupun kelompok, dukungan dapat berupa; empati, kepedulian, dan perhatian terhadap BPM, Dukungan yang diberikan dapat berupa Informatif, pemberian nasihat, saran, pengetahuan, dan informasi serta petunjuk dalam pemberian vitamin $\mathrm{K}_{1}$. Dukungan yang diberikan oleh Departemen kesehatan dapat memberikan dukungan dengan pemberian vitamin $\mathrm{K}_{1}$ jika BPM mau mengamprah ke puskesmas . 
Tabel.9 Hasil Analisis Multivariat Regresi Logistik Antara Pengetahuan, Sikap, Pendidikan, Lama Bekerja, Pelatihan Dan Dukungan Dengan Pemebrian Suntikan Vitamin $\mathbf{K}_{1}$ Pada Bayi Baru Lahir Di Kabupaten Deli Serdang

\begin{tabular}{ccccccc}
\hline Variabel & B & SE & Wald & Sig & B.Exp & 95\% CI \\
\hline Pengeta & -.635 & 0.826 & 0.591 & 0,442 & $0, .530$ & $0.105-$ \\
huan & & & & & & 2.677 \\
Sikap & 2.121 & 0.989 & 4.602 & 0.032 & 8.339 & $1.201-$ \\
& & & & & & 57.900 \\
Pendidi & 2.256 & 0.938 & 5.784 & 0.016 & 9.544 & $1.518-$ \\
kan & & & & & & 59.996 \\
Lama & 2.107 & 0.945 & 4.969 & 0.026 & 8.226 & $1.290-$ \\
Bekerja & & & & & & 52.468 \\
Pelati & 3.514 & 0.806 & 19.019 & 0.000 & 33.598 & $6.924-$ \\
han & & & & & & 163.028 \\
Duku & -.071 & 0.973 & 0.005 & 0.942 & 0.931 & $.138-$ \\
ngan & & & & & & 6.275 \\
Constan & 12.306 & 2.788 & 19.486 & & & \\
\hline -2 Log Likehood=54.159 & G $=49.761$ & P. .000
\end{tabular}

Hasil analisis diatas ternyata semua variabel model ini mempunyai p.value (sig) dibawah 0,05 berarti variabel sikap, pendidikan, lama bekerja dan pelatihan berpengaruh secara signifikan dengan pemberian suntikan vitamin $K_{1}$ pada bayi baru lahir dengan Percentage Correct 87.8 \% dan merupakan model akhir faktor penentu pemberian vitamin $\mathrm{K}_{1}$ pada bayi baru lahir. Dari analisis ini dapat disimpulkan bahwa dari keempat variabel yang berpengaruh dalam pemberian suntikan vitamin $\mathrm{K}_{1}$ pada bayi baru lahir (87,8 \%) dipengaruhi oleh adalah variabel Pelatihan, Sikap, Pendidikan dan Lama bekerja, sedangkan yang paling dominan yang mempengaruhi adalah Pelatihan, dimana nilai B Expectednya paling besar (28.133).

\section{SIMPULAN DAN SARAN}

\section{Simpulan}

Berdasarkan hasil analisis dan pembahasan hasil penelitian, dapat diambil kesimpulan mengenai pemberian suntikan vitamin $\mathrm{K}_{1}$ pada bayi barulahir di Kabupaten Deli Serdang

1. Tidak ada pengaruh pengetahuan BPM dengan pemberian suntikan vitamin $\mathrm{K}_{1}$ pada bayi baru lahir

2. Adanya pengaruh sikap BPM dengan pemberian vitamin $\mathrm{K}_{1}$ pada bayi baru lahir

3. Tidak Ada pengaruh pendidikan BPM dengan pemberian vitamin $\mathrm{K}_{1}$ pada bayi baru lahir

4. Adanya pengaruh lama bekerja BPM dengan pemberian vitamin $\mathrm{K}_{1}$ pada bayi baru lahir

5. Adanya pengaruh pelatihan yang relevan (APN) BPM dengan pemberian vitamin $K_{1}$ pada bayi baru lahir

6. Adanya pengaruh dukungan dari pihak terkait pada BPM dengan pemberian vitamin $\mathrm{K}_{1}$ pada bayi baru lahir
7. Dari uji multivariate terdapat 4 variabel yang mempengaruhi BPM dalam pemberian vitamin $\mathrm{K}_{1}$ pada bayi baru lahir yaitu ; pelatihan, pendidikan, lama bekerja dan sikap

8. Dari ke 4 variabel tersebut diatas, faktor yang sangat dominan mempengaruhi BPM memberikan vitamin $K_{1}$ pada bayi baru lahir yaitu pelatihan dengan nilai B Expected yang paling tinggi yaitu 28,133

A. Saran

1. Berdasarkan kesimpulan diatas pengetahuan responden tidak berhubungan dengan pemberian vitamin $K_{1}$, maka diharapkan pada organisasi profesi (IBI) untuk memberikan penyegaran pada BPM dengan mengadakan pelatihan-pelatihan atau seminar pada BPM untuk dapat meningkatkan pengetahuan, sikap dan kerampilan BPM dalam pelaksanaan tugasnya. Pada saat BPM memperpanjang surat izin praktek diharapkan IBI dapat mengkaji ulang tentang pengetahuannya yang berhubungan dengan tugas praktek mandiri Bidan.

2. Bagi instusi pendidikan, agar dalam masa pendidikan D-III dan D-IV Kebidanan, teori pemberian vitamin $\mathrm{K}_{1}$ pada bayi baru lahir selalu ditekankan, sehingga setelah lulus dan melaksanakan praktek bidan mandiri ada pengaruhnya bagi bidan yang sudah mengikuti cpendidikan D-III dan D-IV terhadap pemberian vitamin $\mathrm{K}_{1}$ pada bayi baru lahir

3. Diharapkan pada peneliti selanjutkan untuk melanjutkan penelitian ini yang berhubungan dengan pelaksanaan tugas mandiri bidan terutama perilaku bidan tentang perlindungan diri BPM dalam pertolongan persalinan

\section{DAFTAR PUSTAKA}

Arikunto, S, 2006. Prosedur Penelitian Suatu Pendekatan Praktik, Jakarta: Rineke Cipta.

BKKBN, 2012. Buku Materi Informasi Kesehatan dan Tumbuh Kembang Anak.

Budjianto D dkk, 2008. Laporan penelitian yang berjudul "upaya peningkatan manajemen pertolongan persalinan dan pasca persalinan oleh bidan di rumah sakit dan fasilitas kesehatan” di Provinsi Jawa Timur, Sulawesi Selatan dan Sulawesi Utara.

Depkes RI, 2010. Peraturan Menteri Kesehatan tentang Izin dan Penyelenggaraan Praktik Bidan.

Dirjen Bina Kesehatan Masyarakat Depkes RI, 2009 pedoman Teknis Pemberian Injeksi Vitamin $K_{1}$ Profilaktis Pada BBL.

HTA Indonesia, 2003. Profilaksis Pemberian Vitamin K pada Bayi Baru Lahir

Kemenkes RI, 2010, Panduan Pelayanan Kesehatan Bayi Baru Lahir Berbasis Perlindungan Anak, Kemenkes RI.

Kosim M. Sholeh, 2003 ; Buku Panduan Manalemen Masalah Bayi Baru Lahir Untuk dokter, Perawat, Bidan di Rumah Sakit 
Rujukan Dasar Penerbit Kerjasama IDAI (UKK Perinatologi) MNH - JHPIEGO Departemen Kesehatan RI.

Murti, B., 1997; Prinsip dan Metode Riset Epidemiologi Penerbit Gajah Mada University Press.

Notoatmodjo, S., 2003; Metodologi Penelitian Kesehatan Penerbit Rineka Cipta.

2007, Promosi Kesehatan \& Ilmu

Perilaku Penerbit Rineka Cipta.

Pengurus Pusat Ikatan Bidan Indonesia, 2010. Bunga Rampai PP IBI
Saifuddin, AB., 2002; Buku Paduan Praktis Pelayanan Kesehatan Maternal Dan Neonatal Penerbit Yayasan Bina Pustaka Sarwono Prawirohardjo.

Sub Dit Kes Bayi dan Anak, 2000. Direktorat Kesehatan Keluarga, Program KHPPIA.

Sudjana., 2003. Metoda Statistika Penerbit Tarsito Bandung.

Wiknyosastro, Gulardi, Hanifa. 2005. Ilmu Kebidanan. Yayasan Bina Pustaka Sarwino Prawirohardjo : Jakarta. 